\title{
A EDUCAÇÃO AMBIENTAL E SUA RELEVÂNCIA NA PRESERVAÇÃO DOS RECURSOS HÍDRICOS
}

\section{ENVIRONMENTAL EDUCATION AND ITS RELEVANCE IN THE PRESERVATION OF WATER RESOURCES}

\author{
Ronaldo D’Elia', Regina de Oliveira Moraes Arruda², Patricia Bulbovas ${ }^{3}$
}

Submetido em: 14/07/2020

Aprovado em: 16/09/2020

\section{RESUMO}

O meio ambiente sofre transformações com a ação predatória do ser humano. No decorrer do tempo, as ações passam a ser agressivas ao ambiente, porque a humanidade, para dar espaço ao progresso, altera e destrói o meio ambiente sem qualquer cuidado com as questões ambientais ou preocupações com o futuro do planeta. A Organização das Nações Unidas preocupada com questões políticas, econômicas, bélicas, sociais, culturais, educacionais e ambientais do mundo, como a erradicação da fome e a mediação da paz entre os países, atém-se, também, à preservação do Meio Ambiente. Por isso, realizam muitas conferências acerca da questão ambiental, conferências estas que resultaram na concepção de Educação Ambiental. A Educação Ambiental, área interdisciplinar, se refere a estudos e pesquisas sobre mudanças significativas na Terra, tais estudos resultam em projetos voltados à preservação da natureza no mundo. A partir disso, cria-se uma série de atitudes voltadas à redução das ações antrópicas causadas no meio ambiente, impulsionadas pelas mudanças climáticas do Planeta Terra. Conscientizar a população da necessidade de preservar os Recursos Hídricos, representados pela água dos rios, das nascentes e dos oceanos, é tarefa de todas as áreas e, uma das soluções pode estar na área educacional.

PALAVRAS-CHAVE: Meio Ambiente. Preservação. Conscientização ambiental.

\section{ABSTRACT}

The environment undergoes changes with the predatory action of human beings. Over time, actions become aggressive to the environment, because humanity, to make room for progress, changes and destroys the environment without any care for environmental issues or concerns about the future of the planet. The United Nations Organization, concerned with political, economic, military, social, cultural, educational and environmental issues in the world, such as the eradication of hunger and the mediation of peace between countries, is also concerned with the preservation of the Environment. For this reason, they hold many conferences on the environmental issue, which resulted in the conception of Environmental Education. Environmental Education, an interdisciplinary area, refers to studies and research on significant changes on Earth, such studies result in projects aimed at the preservation of nature in the world. From this, a series of attitudes are created aimed at reducing anthropic actions caused in the environment, driven by the climatic changes of Planet Earth. Making the population aware of the need to preserve Water Resources, represented by the water in rivers, springs and oceans, is a task for all areas and one of the solutions may be in the educational area.

KEYWORDS: Environment. Preservation. Environmental awareness.

${ }^{1}$ Mestrado em Análise Geoambiental. Correio eletrônico: relia@prof.ung.br.

2Mestrado em Análise Geoambiental. http://orcid.org/0000-0002-5809-265. Correio eletrônico:rarruda@prof.ung.br

3Mestrado em Análise Geoambiental. http://orcid.org/0000-0003-1714-591. Correio eletrônico: patricia.bulbovas@ung.br 


\section{INTRODUÇÃO}

O meio ambiente sofre várias transformações devido à ação predatória do ser humano no decorrer do tempo. Com o surgimento da Revolução Industrial, essas ações passam a ser cada vez maiores e mais agressivas ao ambiente.

A humanidade, para dar espaço ao progresso e ao desenvolvimento das cidades, altera o meio ambiente sem a devida preocupação com as questões ambientais. Essas preocupações são encontradas em diversos registros no percorrer do tempo, o que demonstra o cuidado e os esforços do ser humano para minimizar ações antrópicas e para evitar a degradação da natureza. Diante de tais fatos, a Organização das Nações Unidas para Educação, Ciência e Cultura (UNESCO), em 1968, deu início a uma série de Conferências, com objetivo de buscar soluções para os problemas ambientais (DIAS, 2008).

A partir dessa sequência de conferências, surge a concepção da Educação Ambiental, e o Brasil começa a dar os primeiros sinais de preocupação com o assunto, em decorrência dos movimentos internacionais. A partir desses encontros, houve um aprofundamento nessas questões, firmando-se diversos tratados internacionais, em que vários países se comprometem em praticar ações voltadas à redução das atividades antrópicas impactantes, as quais impulsionam as mudanças climáticas do planeta Terra. Nesse cenário, um dos agentes preocupantes é a água, por ser essencial à existência dos seres vivos.

A Educação Ambiental (EA), por fazer parte do cenário mundial, torna-se algo tão primordial que foi incluída nos Parâmetros Curriculares Nacionais (PCN), passando a ser um instrumento importante para conscientizar e preservar o meio ambiente. Por essa razão, o Ministério da Educação e Secretaria de Educação do Ensino Fundamental, por meio do PCN incluiu a EA no ensino formal, adotando em seus currículos as práticas da questão ambiental (BRASIL, 1997).

No Ensino Fundamental é o momento em que o docente tem a condição de realizar uma sensibilização dos problemas ambientais, visto que no ensino básico a proposta é focada nas questões psicológicas, utilizando os sentidos para que a criança possa imaginar, sentir e descobrir, através das relações interpessoais, fenômenos da natureza. Por outro lado, no Ensino Fundamental, o discente já possui capacidade de investigação e de compreensão de mundo e do meio ambiente. Por meio de atividades práticas e de conteúdos para a conscientização discente, o docente pode aproveitar as áreas de ensino relacionando a tônica ambiental de forma transversal entre as disciplinas (ANANIAS, 2012).

O objetivo deste trabalho foi apresentar um histórico da Educação Ambiental e demonstrar como a preservação dos Recursos Hídricos está alinhada à essa questão.

\section{FUNDAMENTAÇÃOTEÓRICA}

\section{Surgimento da Concepção da Educação Ambiental}

Com o passar do tempo, observamos vários registros de diversos acontecimentos sobre a luta pela preservação e qualidade ambiental, tanto internacionalmente, como no Brasil, os quais são constados em diferentes conferências, programas e projetos com abordagem do Meio Ambiente (POLETO, 2014).

De acordo com Gonçalves (1990), a forma de produzir e de viver da sociedade está relacionada com o modo de agir e de pensar dos seres humanos com relação à natureza desde muitos séculos passados. Observando-se o pensamento ocidental, nota-se que algumas obras de filósofos da Grécia e Roma clássicas e a tradição judaico-cristã, os quais são a base da cultura ocidental, há vários indícios de certos valores presentes na sociedade atual, como antropocentrismo e a visão dicotomizada entre o ser humano e a natureza.

No ano 111 a.C., Platão já denunciava a ocorrência de desmatamento e erosão de solos nas colinas da Ática, na Grécia, ocasionado pelo excesso de pastoreiro de ovelhas e cortes de madeira. O avanço do crescimento da Idade Média, que alcançou o seu auge no século XIII, trouxe o escasseamento da madeira em decorrência do desmatamento de florestas. Para minimizar esse problema, no início do século XVI, a França proibiu o funcionamento das serrarias hidráulicas com o intuito de minimizar os impactos, e a Inglaterra determinou que as suas florestas fossem protegidas por lei (ACOT, 1990).

Segundo Philippi Junior e Pelicioni (2014), em 1661, o memorialista e naturalista John Evelyn já fazia relatos dos problemas com a poluição do ar devido à queima do carvão, um problema sério naquela época. 
A poluição ácida é um problema comum atualmente $\mathrm{e}$ já era notada no século XVII por John Evelyn e John Graunt, que demonstraram que as emissões industriais estavam ligadas aos problemas de saúde das pessoas e plantas, na França. Como solução, era elevada a altura das chaminés para melhor dispersar a poluição.

Já no século XIX, o naturalista alemão Humboldt, chama atenção para a questão hídrica de um lago na Venezuela devido ao desmatamento em suas margens. O norte-americano Geirge Perkins Marsh, diplomata e político, em 1864 chamou/atenção para a interferência humana no meio ambiente (ACOT, 1990).

De acordo com Pádua (1987), em 1883 algumas figuras brasileiras chamavam atenção, como José Bonifácio de Andrade e Silva, que condenava a escravatura e a destruição ambiental. Joaquim Nabuco que denunciava o esgotamento da fertilidade dos solos no Rio de Janeiro, da decadência das antigas monoculturas no Nordeste, o aumento do flagelo da seca e a ganância da indústria extrativista na Amazônia, entre outros. Rebouças sugeria a criação de áreas protegidas na Ilha do Bananal e Sete Quedas.

Desde a Revolução Industrial, a atividade interventora e transformadora do homem em sua relação com a natureza vem tornando-se cada vez mais predatória. A década de 1960 pode ser considerada como uma referência quanto à origem das preocupações com as perdas da qualidade ambiental (TOZONIREIS, 2004, p. 3).

Após o fim da Segunda Guerra Mundial, em 1946 na Basiléia, um novo Congresso é realizado pela Liga Suíça para Proteção da Natureza, com intenção à Proteção Internacional da Natureza. Logo após, em 1948, criou-se a União Internacional para a Conservação da Natureza e dos Recursos Naturais (UICN), com objetivo de assegurar a perpetuidade dos Recursos Naturais, tendo como base científica para formação e dinâmica dos ecossistemas. No ano de 1951, esse organismo publicou um estudo que recebeu o nome de Estado da proteção da natureza no mundo em 1950, em que continha setenta relatórios de diversos países. Por intermédio da UNESCO, a UICN interveio junto a vários governos e participou de diversos encontros internacionais (ACOT, 1990).
Em Paris, em 1968, a UNESCO promoveu um congresso sobre conservação e o uso racional dos recursos da biosfera, estabelecendo o programa Homem e a Biosfera (DIAS, 2008).

Em meados dos anos 1970 na Suécia, as Nações Unidas promoveram uma proposta de realizar um Congresso Mundial para discutir o Meio Ambiente, fato que se concretizou em 1972 em Estocolmo. Esse congresso foi o primeiro convocado pela Organização das Nações Unidas (ONU), onde houve participação de vários governos e estudiosos para discutir sobre Educação Ambiental (SATO; CARVALHO, 2005).

No congresso de Estocolmo, firmou-se a carta de Belgrado, alterando os objetivos da EA como consciência, conhecimentos, comportamentos, aptidões e participação. Essa foi à primeira conferência temática da ONU e reuniu representantes de 113 países (McCORMICK, 1992).

As preocupações pedagógicas passam a ser um processo cognitivo de soluções ambientais, materiais de ensino e os conteúdos, bem como os métodos interdisciplinares (SATO; CARVALHO, 2005).

Lançadas as bases de uma legislação internacional concernente ao meio ambiente, onde se uniu a proibição do armamento atômico aos grandes problemas ecológicos, e onde a discriminação racial, o apartheid e o colonialismo foram condenados (PHILIPPI JUNIOR; PELICIONI, 2014, p. 427).

A partir do reconhecimento da relação entre meio ambiente e desenvolvimento, com base nessas preocupações ambientais, surge a recomendação da implementação de um programa de EA, como elemento fundamental para combater a crise ambiental. Em 1973, foram criados programas fundamentais como o Programa das Nações Unidas para o Meio Ambiente - PNUMA/United Nations Environment Programme (UNEP) e o Programa Earth Watch, com objetivo de monitorar a poluição ambiental (ACOT, 1990).

A partir desse decênio, no mundo começam a aparecer vários estudos sobre EA, e consequentemente - Brasil passa a desenvolver propostas sobre EA, propiciando várias reflexões sobre o assunto (SATO; CARVALHO, 2005).

Com o reverbero das ações da UNESCO, 
ocorre uma elevação das preocupações ambientais. Assembleia geral da ONU criou em 1983 a Comissão Mundial sobre o Meio Ambiente e o Desenvolvimento (CMMAD), onde tinha como foco principal examinar as relações entre meio ambiente e o desenvolvimento, com a finalidade de expor propostas viáveis (DIAS, 2008).

De acordo com Viola e Leis (1992), o Brasil, somente a partir de 1981 deixou de ser o campeão mundial do crescimento econômico. Nesse momento a sociedade brasileira começa a ter consciência ambiental, porque passou a observar claramente que o modelo que havia adotado era extremamente poluidor e degradador dos recursos naturais, além ter ocasionado assimetrias sociais significativas. Foi na década 80 , que o ambientalismo brasileiro deixa de ser restrito a pequenos grupos da sociedade e do estado, e passa a contar com estímulos de movimentos sociais, Organizações não Governamentais (ONGs), Universidades, mídias e empresas. Essa mudança ocasionou a ampliação do escopo de atuação da Secretaria do Estado do Meio Ambiente (SEMA), a qual foi disseminada em toda estrutura estatal, fazendo a interação entre as agências ambientais e a comunidade científica, viabilizando o funcionamento do Conselho Nacional do Meio Ambiente (CONAMA).

O ano de 1988 também constituiu um marco importantíssimo na política ambiental brasileira ao assegurar, na Constituição Federal (BRASIL, 1997), um capítulo dedicado ao meio ambiente, onde se lê: Art. 225. Todos têm direito ao meio ambiente ecologicamente equilibrado, bem de uso comum do povo e essencial à saúde qualidade de vida, importando-se ao poder público e à coletividade o dever de defendê-lo e preserválo para presente e futuras gerações (PHILIPPI JUNIOR; PELICIONI, 2014, p. 434).

Em 1992 no Rio de Janeiro - Brasil, ocorre o Congresso das Nações Unidas sobre o Desenvolvimento e Meio Ambiente, conhecida como Rio-92, em que se confeccionou a Carta Terra, na qual cada país foi designado a desenvolver um conjunto de propostas com foco na reversão no processo de degradação do meio ambiente. Apenas em 1997, na Grécia, no III Congresso Internacional do Meio Ambiente, que aparece a preocupação com a tônica Educação para - Desenvolvimento Sustentável. No Congresso de Genebra - Suíça, em 1996, teve como proveniência a Declaração de Genebra, cujos países conseguiriam apoio financeiro para diminuição de gases poluentes, com verbas do Fundo Global para o Meio Ambiente (SATO e CARVALHO, 2005).

Em dezembro de 2000, a Reunião Geral das Nações Unidas decidiu que a Comissão Sobre Desenvolvimento Sustentável (CDS) serviria ao Órgão Central organizador da Cúpula Mundial de Desenvolvimento Sustentável, conhecida como Rio +10 , que ocorreria em Johanesburgo, em 2002, para analisar a situação do meio ambiente global em função das medidas adotadas na Conferência das Nações Unidas sobre o Meio Ambiente e o Desenvolvimento (CNUMAD)-92 (DIAS, 2008).

\begin{abstract}
Em um mundo tão concatenado como o de hoje a inclinação das ONGs pela postura ambiental de determinado governo pode significar uma alternativa de influenciar o processo de negociação bilateral com os países desenvolvidos, em especial as grandes potências, na questão ecológica. A busca dessa simpatia poderia vir a ter repercussões nas políticas internas dos diferentes países, que procurariam dar respostas institucionais as pressões externas em favor da preservação e manejo nacional do meio ambiente (CANÍZIO, 1990, p. 46).
\end{abstract}

Segundo Philippi Junior e Pelicioni (2014), no ano de 2003, em Portugal, na cidade de Espinho, com o patrocínio do PNUMAe UNESCO, foi realizado o primeiro Congresso Mundial de Educação Ambiental, com foco à Estratégia para um Futuro Sustentável (Strategies for Sustainable Future). Posteriormente ocorreu o segundo congresso, em 2004, no Rio de Janeiro, com foco num futuro possível (Building a Possible Future). Em 2005, na Itália, em Turim, no terceiro Congresso Mundial de Educação Ambiental, a tônica foi os Caminhos Educacionais para a Sustentabilidade (Educational Paths Towards Sustainability). Em Durban, na África do Sul, em 2007, ocorreu o quarto Congresso para discutir aprendizagem em um mundo em mudança (Learning In a Changing World). O quinto evento, em 2009, em 
Montreal, no Canadá, a tônica foi a Terra, nossa casa comum (The Earth, our common home).

Em 2009, acorre em Bonn, Alemanha, a reunião para discutir os principais textos de negociação das tônicas relacionadas às alterações climáticas com a presença de 183 países. Em Cancun, no México, no ano de 2010, as partes reuniram-se para Criação do Fundo Verde do Clima, que é um fundo para os países em desenvolvimento financiarem ações para deter as mudanças climáticas (POLETO, 2014).

No ano de 2011, ocorreu o sexto Congresso Mundial de Educação Ambiental, na Austrália, na cidade de Brisbane, com enfoque em Explorar, Experiência, Educar (Explore, Experience, Educate). No Marrocos em Marrakesh, em 2013, ocorreu o oitavo Congresso, tendo a participação de 2400 pessoas de 105 países, com a temática Educação Ambiental em Cidades e Áreas Rurais: Busca por Maior Harmonia. Esses eventos são importantes para troca de experiências com contextos diversos e que geram documentos para dar apoio a projetos por parte de autoridades públicas, instituições, entre outras questões, esperando-se que as recomendações e os compromissos presentes nos documentos resultantes desses eventos sejam concretizados (PHILIPPI JUNIOR; PELICIONI, 2014).

\section{EDUCAÇÃO AMBIENTAL E A ESCOLA}

De acordo com Ananias (2012), a Educação Ambiental (EA) passou a fazer parte do cenário social e político no mundo nos últimos 50 anos, onde foram feitos diversos documentos por ambientalistas, chamando atenção para os riscos e as consequências que podem ocorrer da relação entre ambiente e ser humano, em virtude da ação antrópica. Diante dessa situação, os PCN - Temas Transversais deixam evidente que as questões ambientais na escola passam a ser um instrumento essencial para conscientização do indivíduo, como o objetivo de criar um hábito de preservação do meio ambiente. Ocorre que muitos desses docentes não tiveram formação ou qualquer conhecimento teórico e metodológico para lecionar temas da EA.

De Andrade Saraiva et al. (2017) afirmam que a educação tradicional adotou em seu currículo as práticas da questão ambiental, utilizando o professor como instrumento para conscientizar o discente dos problemas ambientais, tornando esse indivíduo como um agente modificador de práticas na sociedade, introduzindo preceitos da sustentabilidade, tornandoos multiplicadores do tema em questão. As instituições de ensino se pautam de leis e decretos Municipais, Estaduais e Federais para elaborar seus currículos escolares, baseando-se no contexto da localização da instituição de acordo com as condições políticas, sociais e econômicas.

De acordo com as Diretrizes Curriculares da Educação Básica, para o planejamento curricular, se faz necessário selecionar os conteúdos de acordo com a vida social do discente, pensando no segmento da sua vida acadêmica, com objetivo de que os conhecimentos abordados sejam significativos, de forma a favorecer a participação ativa dos alunos (BRASIL, 2013).

\section{Se a escola não pode proporcionar todas as informações científicas que os cidadãos necessitam, deverá, ao longo da escolarização, propiciar iniciativas para que os alunos saibam como e onde buscar os conhecimentos que necessitam para a sua vida diária. Os espaços não formais compreendidos como museu, zoológico, parques, fábricas [...] [...] constituem fontes que podem promover uma ampliação do conhecimento dos educandos. As atividades pedagógicas desenvolvidas que se apoiam nestes espaços, aulas práticas, saídas a campo, feiras de Ciências, por exemplo, poderão propiciar uma aprendizagem significativa contribuindo para um ganho cognitivo (LORENZETTI; DELIZOICOV, 2001, p. 7).}

De acordo com as Diretrizes Curriculares Nacionais para a Educação Básica, a EA é realizada através de uma construção conceitual, que através das práxis educacionais na maioria das vezes por teorias correlacionadas, fracionadas e forma partidária da problemática ambiental, com abordagens despolitizadas e simples dessa temática. Essa diretriz menciona ainda que, no início foi em decorrência de uma tradição naturalista, e nos dias atuais ainda se convive com esse fracionamento da realidade, fortalecendo a dicotomia que há entre natureza e homem. Diante dessa retórica essa visão socioambiental tem que ocorrer uma quebra 
de paradigma, para se construir uma interação entre o homem e a natureza (BRASIL, 2013).

De acordo com Minéu; Teixeira; De Muno Colesanti (2016), o currículo escolar é um saber no qual se constrói em um espaço. Diante desse dilema é necessário realizar aproximação do currículo comum com as dificuldades em se alcançar os objetivos da educação e dos conteúdos programáticos. Essas dificuldades aparecem na elaboração de um currículo que contemple diversidade de valores e culturas de uma sociedade aberta e pluralista. Nota-se que no passado esses currículos eram definidos com conteúdos vedados e baseados em estudos de conceitos abstratos, sem qualquer vínculo com o uso social. O que se busca atualmente é contextualizar conteúdos do currículo por meio de temas transversais, partindo de questões emergentes.

Segundo Philippi Junior; Roméro; Bruna (2014), a abordagem sociocultural favorece que ocorra uma ação proativa e transformadora. A proposta EA, para se efetivar, implica em formação para uma reflexão crítica. O Educador, não aquele que educa, mas sim aquele que propicia um ambiente favorável, para que o conhecimento seja absorvido pelo educando. $O$ discente somente irá colocar em prática e fará parte de sua vida, se o conhecimento adquirido for aceito como verdade.

De acordo com Santos (2004), a participação pela educação é primordial para o planejamento. A Educação e a participação da escola são elementos fundamentais para os planejadores e educadores criarem um objetivo comum favorecendo um elo entre as partes. Pois dessa forma criam uma relação estreita entre planejadores e educadores para obter soluções dos problemas ambientais prioritários, tendo uma participação concreta de grupos sociais. O caminho para tomar decisões, concomitantemente, procura verificar, discutir e estimular as possibilidades de mudanças de hábitos, opiniões e práticas cotidianas. Dessa maneira, podem ocorrer mudanças sem perder o objetivo do contexto político, econômico, social, ambiental e cultural dos grupos envolvidos. Criando uma participação efetiva para que os planejadores enxerguem a comunidade envolvida como sujeito e não como objetivo do planejamento.

\section{EDUCAÇÃO AMBIENTAL E OS RECURSOS HÍDRICOS}

No Brasil, em 1973 foi criado a SEMA, com objetivo de incorporar oficialmente a EA em seus programas, e intuito de atender as exigências internacionais, junto com o Instituto Brasileiro do Meio Ambiente e dos Recursos Naturais Renováveis (IBAMA). Esses dois órgãos organizam cursos voltados para EA, de caráter interdisciplinar. Porém a responsabilidade da distribuição de água no Brasil é da Agência Nacional de Águas (ANA), que fez a divisão das bacias Hidrográficas no país, que serve como referência para o gerenciamento dos recursos Hídricos (ROSA; FRANCETO; MOSCHINICARLOS, 2013).

A partir de 2006 é consolidada a importância dos recursos hídricos no Brasil, com a criação da lei $n^{\circ}$ 9.433/97, que trata da Política Nacional dos Recursos Hídricos (PNRH). Tal criação foi em função do atendimento das assembleias internacionais, e adotou uma gestão integrada e participativa das águas, dando peso a uma gestão participativa. Diante disso, houve um processo sistemático de educação e cooperação entre diversos agentes públicos e privados com esforços voltados para formação de pessoal (BRASIL, 2006).

No PNRH, a conexão com EA aparece de forma inicial nesse plano, contudo ao prever a articulação e a integração com outras políticas públicas correlatas, ele não menciona em seu escopo de políticas públicas a educação, ressaltando apenas a saúde, saneamento e energia. Porém a Gestão Integrada de Recursos Hídricos (GIRH), menciona sobre a Capacitação e Educação ressaltando a questão Ambiental. No entanto, destaca no que tange $E A$, que o desenvolvimento fica restrito a temáticas e metodologias de interesse da $\mathrm{GIRH}$, mantendo a execução descentralizada aos estados e aos comitês de bacias hidrográficas, considerando as diretrizes básicas da Agenda 21, do Tratado de Educação Ambiental para Sociedades Sustentáveis e da Carta da Terra (BICUDO, TUNDISI e SCHEUENSTUHI, 2010).

É extremamente relevante que o docente busque atuar com uma gestão participativa nas questões hídricas, utilizando a EA para fortalecer e propor atividades nesse tema (BICUDO, TUNDISI e SCHEUENSTUHI, 2010). Como o objetivo de auxiliar o docente, com relação à educação ambiental foram propostas três categorias de EA, conforme quadro 1. 
Quadro 1. Concepções de Educação Ambiental.

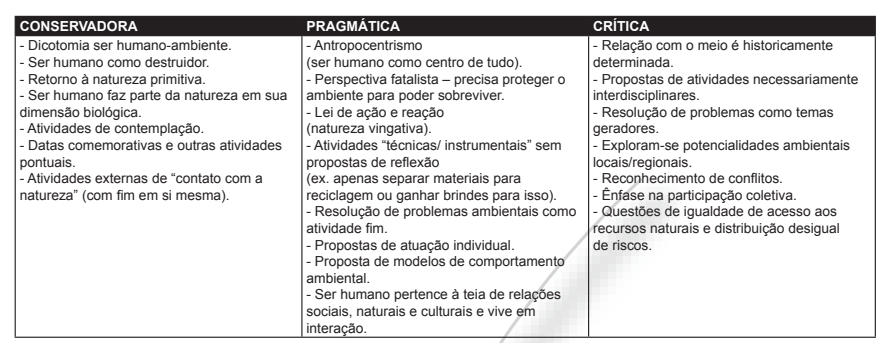

Fonte: Bicudo, Tundisi e Scheuenstuhi (2010, p. 133).

Diante do Tratado de Educação Ambiental para Sociedades Sustentáveis e de Responsabilidade Global, assinado durante a Rio-92, e pensando na gestão participativa como formação, tem como destaque em caráter permanente da $\mathrm{EA}$, a busca por uma construção de sociedades socialmente justas e ecologicamente sustentáveis. De acordo com a Lei no 9795/99, a Política Nacional de Educação Ambiental, estabelece que a EAé um processo por meio do qual o indivíduo e a coletividade constroem valores sociais, conhecimentos, habilidades, atitudes e competências voltadas para a conservação do meio ambiente e bem de uso comum do povo, essencial à sadia qualidade de vida e sua sustentabilidade, e é semelhante com a PNRH (BRASIL, 2006).

Os PCN editados pelo Ministério da Educação trazem a questão ambiental como um tema transversal. No bloco meio ambiente a água é utilizada como eixo importante para se trabalhar a ideia de ciclo, envolvendo os recursos hídricos. O trabalho de EA deve ser desenvolvido para ajudar os discentes a construírem uma consciência global das questões relativas ao meio ambiente, para que possam assumir posição com valores, a fim de também atribuir um significado com valores quanto a proteção e melhoria do meio ambiente. Por essa razão é tão importante que aprendam sobre a questão ambiental (BRASIL, 1997).

De acordo com Oliveira, Machado e Oliveira (2015), a Educação Ambiental traz novas premissas de comportamento e do papel do ser humano com relação ao planeta, e a escola tem uma importância fundamental, para conscientizar os discentes de suas ações quanto à preservação dos recursos naturais, visto que água é a vida do Planeta Terra. A EA precisa ser inserida nas escolas, pois os discentes passam um bom tempo tendo contato com novos conceitos e, ao abordarem temas relacionados à conservação dos recursos hídricos, haverá assimilação do assunto e surtirá efeito no futuro, preparando-o a obter um pensamento crítico sobre o ambiente.

\begin{abstract}
A batalha da formação do homem pode ser definida como vencida ou vencedora na Educação Infantil e, também, no Ensino Fundamental. É nesse mundo, cujas lembranças carregamos num lugar especial de nossos corações, que se travou a mais bela batalha para se erguer e afirmar o que somos hoje (BRANCO, 2007, p.5).
\end{abstract}

O tema Recursos Hídricos é tão complexo que exige uma atenção especial na educação. Devido a água ser um elemento essencial para existência dos seres vivos, o docente ao tratar de bacias hidrográficas precisa ter conhecimento para ter capacidade de explorar o meio ambiente, ter condições de contextualizar o assunto em suas aulas, como tema central a discussão da história ambiental. Este fato acaba proporcionando um direcionamento ao discente sobre as diferenças e os problemas entre naturais e antrópicos, que modificam o ambiente. A ocupação humana e ações da sociedade, ao se apropriar dos espaços físicos, acabam interferindo em diversos fatores, provocando a degradação das bacias hidrográficas em prol de seus interesses, seja no meio rural ou urbano. $O$ docente, ao trabalhar no âmbito da bacia hidrográfica, contribui para o entendimento do contexto, e com base na história ambiental, promove estratégias de aprendizagem que podem contribuir para as práticas pedagógicas para ensinar sobre o recurso água na terra, partindo da sua origem, ciclo hidrológico e aquíferos. Após esse entendimento, é possível relacionar os problemas que vão desde riscos geológicos até a gestão dos recursos hídricos, proporcionando ao aluno uma visão abrangente para uma negociação dos usos múltiplos (BACCl; PATACA, 2008).

\section{CONSIDERAÇÕES FINAIS}

O movimento mundial pela Educação Ambiental se tornou mais presente a partir da segunda guerra mundial. E o Brasil esteve atento a essas questões contemplado esse assunto em diversas legislações, e principalmente nos Parâmetros Curriculares Nacionais.

As diretrizes e planos diretores das escolas mencionam a questão da transversalidade ao se tratar da 
Educação Ambiental, porém o fato desse conteúdo não estar em uma disciplina específica faz com que o mesmo seja abordado com profundidades diferentes. O tema água se mostra bastante interessante para a Educação Ambiental, e pode ser trabalhado em várias disciplinas e em níveis que vão do Fundamental I até o Ensino Médio. Podemos trabalhar desde uma torneira pingando até projetos visando captação, armazenamento e uso de água de chuva.

A educação ambiental com o tema recursos hídricos estimula cada cidadão a pensar como o mesmo está cuidando da água. A educação é importante tanto na conservação das nascentes e rios como no entendimento que o uso da água deve ser consciente e sem desperdícios.

\section{REFERÊNCIAS}

ACOT, Pascal. História da ecologia. 2. ed. Rio de Janeiro: Campus, 1990.

ANANIAS, Natália Teixeira. Educação Ambiental e água: concepções e práticas educativas em escolas municipais. 2012. 175 f. Dissertação (Mestrado) Universidade Estadual Paulista, Faculdade de Ciências e Tecnologia, Programa de Pós-Graduação, 2012. Disponível em: http://hdl.handle.net/11449/92242. Acesso em: 03 maio 2020.

BACCI, Denise de La Corte; PATACA, Ermelinda Moutinho. Educação para a água. Estudos Avançados, São Paulo, v. 22, n. 63, p. 211-226, jan. 2008. DOI: http://dx.doi.org/10.1590/S0103-40142008000200014. Disponível em: http://www.journals.usp.br/eav/article/ view/10302. Acesso em: 03 maio 2017.

BICUDO, Carlos Eduardo de Mattos; TUNDISI, José Galisia; SCHEUENSTUHI, Marcos Cortesão Barnsley. Águas do Brasil Análise Estratégicas. São Paulo: Instituto de Botânica, 2010.

BRANCO, Sandra. Meio ambiente - educação ambiental na Educação Infantil e no Ensino Fundamental - Oficinas aprender fazendo. São Paulo: Cortez, 2007.

BRASIL. Secretaria de Educação Fundamental. Parâmetros Curriculares Nacionais: meio ambiente, saúde. Brasília: Secretaria de Educação Fundamental, 1997.

BRASIL. Ministério do Meio Ambiente. Plano Nacional de Recursos Hídricos: Síntese Executiva. Ministério do Meio Ambiente. Brasília: Secretaria de Recursos Hídricos, 2006.

BRASIL. Ministério da Educação. Secretaria de Educação Básica. Diretoria de Currículos e Educação Integral. Diretrizes Curriculares Nacionais para a Educação Básica. Brasília: Secretaria de Educação Básica, 2013.

CANÍZIO, Márcia Jabôr. Ecologia e ordem Internacional: uma discussão sobre os paradigmas de análise. Rio de Janeiro: Contexto Internacional, 1990.

SARAIVA, Marianna de Andrade. et al. Educação Ambiental: a criança como um agente Multiplicador (AÇUDE VIVO No XI002008PJ022). Encontros Universitários da UFC, v. 1, p. 3764, 2017.

DIAS, Reinaldo. Gestão Ambiental: responsabilidade social e sustentabilidade. São Paulo: Atlas, 2008.

GONÇALVES, Carlos Valter Porto. Os (des) caminhos do meio ambiente. 2. ed. São Paulo: Contexto, 1990.

LORENZETTI, Leonir; DELIZOICOV, Demétrio. Alfabetização científica no contexto das séries iniciais. Ensaio-Pesquisa em Educação em Ciências, v. 3, n. 1, jun. 2001.

McCORMICK, John. Rumo ao paraíso: a história do movimento ambientalista. Rio de Janeiro: RelumeDumará, 1992.

MINÉU, Humberto Ferreira Silva; TEIXEIRA, Raquel Alves; DE MUNO COLESANTI, Marlene. A Educação Ambiental no currículo escolar do ensino médio da rede estadual de Minas Gerais. AMBIENTE \& EDUCAÇÃORevista de Educação Ambiental, v. 19, n. 2, p. 18-32, 2016.

OLIVEIRA, Jeane Teresinha de; MACHADO, Rita de Cássia Dallago; OLIVEIRA, Everton Mário de. 
Educação Ambiental na Escola: um caminho para aprimorar a percepção dos alunos quanto à importância dos Recursos Hídricos. Periódico Eletrônico Fórum Ambiental da Alta Paulista, [S.I.], v. 11, n. 4, dez. 2015. DOI: Http://Dx.Doi.Org/10.17271/1980082711420 151293 Disponível em: https://www.amigosdanatureza. org.br/publicacoes/index.php/forum_ambiental/article/ view/1293. Acesso em: 03 maio 2017.

PÁDUA, José Augusto. Natureza e projeto nacional: as origens da ecologia política no Brasil. In: Ecologia e política no Brasil. Rio de Janeiro: Espaço e Tempo/ IUPERJ, 1987.

PHILIPPI JUNIOR, Arlindo; ROMÉRO, Marcelo de Andrade; BRUNA, Gilda Collet. Curso de Gestão Ambiental. 2. ed. São Paulo: Manole, 2014.

PHILIPPI JUNIOR, Arlindo; PELICIONI, Maria Cecília Focesi. Educação Ambiental e Sustentabilidade. 2. ed. São Paulo: Manole, 2014.

POLETO, Cristiano. Bacias Hidrográficas e Recursos Hídricos. São Paulo: Editora Interciência, 2014.

ROSA, André Henrique; FRANCETO, Leonardo Fernandes; MOSCHINI-CARLOS, Viviane. Meio Ambiente Sustentabilidade. Porto Alegre: Bookman, 2012.

SATO, Michele; CARVALHO, Isabel. Educação ambiental: pesquisa e desafios. Porto Alegre: Artmed, 2005.

SANTOS, Rosely Ferreira dos. Planejamento ambiental: teoria e prática. São Paulo: Oficinas de textos, 2004.

TOZONI-REIS, Marília Freitas de Campos. Educação ambiental: natureza razão e história. Campinas: Autores associados, 2004.

VIOLA, Eduardo José; LEIS, Hector Ricardo. Desordem global da biosfera e a nova ordem internacional: o papel organizador do ecologismo. In: LEIS, H.R. (org.). Ecologia e política mundial. Petrópolis: Vozes, 1991. 